Carmen Gloria Pérez Villar *

\title{
Solución de controversias en el Tratado de Libre Comercio con Canadá como modelo para futuras negociaciones.
}

*Abogado y Administrador Público. Profesora de Derecho Internacional Público, Universidad Católica de Valparaiso $y$ Derecho Internacional Privado, Universidad de Valparaíso.

\section{I.- Introducción.}

Nos interesa especialmente este acuerdo porque es uno de los más amplios que ha suscrito nuestro país y es, además, el modelo que, se supone, seguirá Chile en la suscripción de este tipo de tratados, de hecho así ya ocurrió con el tratado que le ha seguido en esta materia suscrito el año 1999 con México' . Hay que hacer presente que el original formato de este tratado, que dista mucho de los acuerdos ya suscritos sobre este tipo de materias, hace bastante más difícil su estudio para familiarizarse con él y ello se debe a que sigue el modelo anglosajón, básicamente al NAFTA².

Nos parece que el tema de la solución de las controversias es uno de los aspectos más importantes para considerar si un tratado puede calificarse de completo y es, justamente, esta materia la que, por cierto, no tuvo un tratamiento adecuado en tratados tan importantes como lo es el Acuerdo de Complementación Económica suscrito con MERCOSUR, siendo esta, además, una de las materias más criticadas del mismo, ya que impide que el tratado sea operativo por sí mismo, y deja a los participantes desprovistos de una herramienta adecuada a la hora de tener que resolver un conflicto nacido con ocasión del tratado.

Es por ello que hemos querido revisar estas normas para tener un parámetro de lo que en esta materia se espera como mínimo de un tratado.

Así, en estas líneas solo haremos una descripción del mecanismo, para plantear, a grandes rasgos, nuestra percepción acerca de él. No son mayores nuestras pretensiones que conocer este aspecto del tratado, que en su conjunto, tiene cerca de mil páginas, por lo que un estudio acabado del mismo solo puede ir por partes.

1 D.S. 1.101, M. RREE, D. Of. 31 de junio, de 1999.

2 Tratado de Libre Comercio suscrito entre EEUU, Canadá y México. 


\section{II.- Regulación de la materia.}

El tema está tratado en el "Capítulo N" del Tratado, que se denomina "Disposiciones institucionales para la solución de controversias", y que cuenta con 21 artículos y 3 anexos que los complementan ${ }^{3}$. La sección I, se refiere a las instituciones que participan, donde se establece la "Comisión de Libre Comercio", que está integrada por representantes de las Partes a nivel de Secretaría de Estado, o por las personas a quienes estos designen.

Entre las funciones que se le asignan a esta comisión está el resolver las controversias que pudiesen surgir respecto a la interpretación o aplicación del tratado.

La Comisión debe establecer un secretariado que estará integrado por secciones nacionales, las que a su vez deben establecer oficinas permanentes.

La sección II se denomina "Solución de controversias", y el artículo N-03 se refiere a la cooperación en los siguientes términos: "Las Partes procurarán, en todo momento, llegar a un acuerdo sobre la interpretación y la aplicación del Tratado y, mediante la cooperación y consultas, se esforzarán siempre por al canzar una solución mutuamente satisfactoria de cualquier asunto que pudiese afectar su funcionamiento".

Este tipo de cláusula que es de estilo en todo procedimiento de solución de controversias, nos parece, no presenta mayor utilidad, por cuanto, de seguro, las Partes ya han intentado un acercamiento para tocar el problema y ciertamente no han podido solucionarlo, de manera que en la generalidad de los casos esta etapa ha sido ya superada.

\section{III.- Ámbito de aplicación.}

El artículo N-04 se denomina "Recurso a los procedimientos de solución de controversias", y en él se indica que las disposiciones para la solución de controversias de este capítulo, se aplicarán a la prevención o a la solución de todas las controversias entre las Partes relativas a la aplicación o a la interpretación de este tratado, o en toda circunstancia en que una Parte considere que una medida vigente o en proyecto de otra Parte, es o podría ser incompatible con las obligaciones de este Tratado, o pudiera causar anulación o menoscabo en los términos explicitados en el Anexo N-04.

Este anexo señala que las Partes podrán recurrir al mecanismo de solución de controversias de este capítulo, cuando en virtud de la aplicación de una medida que no contravenga el tratado, consideren que se anulan o menoscaban los beneficios que razonablemente pudieron haber esperado recibir de la aplicación de las disposiciones sobre comercio transfronterizo de bienes y servicios, excluyéndose algunas materias, en los términos que en el mismo se indican.

3 Los artículos se numeran del $\mathrm{N}-01$ al $\mathrm{N}-21$ y los anexos complementarios a los artículos pertinentes son señalados de la siguiente forma: Anexo N-01.2 “Comités y Grupos de Trabajo”; Anexo N-02.2 “Remuneración y pago de Gastos", y Arexo N-04 "Anulación y menoscabo". 
En el artículo que le sigue se da, también, la posibilidad de resolver las controversias conforme a los mecanismos de la OMC. (Art. N-05).

\section{IV.- Mecanismos de solución que contempla el tratado.}

\section{1). Las Consultas previas.}

El Tratado señala que cualquier Parte podrá solicitar por escrito a la otra la realización de consultas respecto de cualquier medida adoptada o en proyecto, o respecto de cualquier otro asunto que considere pudiere afectar el funcionamiento del acuerdo. Esta es una medida previa al procedimiento de solución de controversias propiamente tal y que, sin duda está siempre abierto a cualquier Parte aunque el Tratado no lo dijera pues aún estamos en el ámbito netamente voluntario, donde las Partes harán todo lo posible, según lo dice el propio artículo N-06, por alcanzar una solución mutuamente satisfactoria de cualquier asunto.

Hay diferencias en los plazos, pues cuando se trata de bienes agrícolas perecederos, las consultas se iniciarán dentro de un plazo de 15 días a partir de la fecha de entrega de la solicitud.

\section{2). Procedimiento ante la Comisión. Artículo N-O7(4).}

Inicio.

Una vez superadas las etapas anteriores, tenemos realmente configurada la controversia y en un punto en que las Partes no han podido solucionar por sí mismas la dificultad. Entonces el Tratado dispone que cualquiera de ellas podrá solicitar (por escrito) que se reúna la Comisión ya que no han logrado resolver el asunto conforme al procedimiento de consulta en los plazos que se señala (30 días después de la entrega de la solicitud para las consultas comunes y 15 días para consultas relativas a bienes agrícolas perecederos), y, por cierto, cualquier otro plazo que pudieren acordar, expresamente y de común acuerdo, las Partes.

La Parte solicitante deberá mencionar en la solicitud la medida o el asunto que sea objeto de la reclamación, deberá indicar también las disposiciones de este Tratado que considere aplicables. La solicitud debe entregarse en su sección del Secretariado y a la otra Parte. Salvo que se decida otra cosa, la Comisión se reunirá dentro de los 10 días siguientes a la entrega de la solicitud y se abocará sin demora a la solución de la controversia. Art. N-0(4).

Alternativas de solución ante la Comisión:

Para apoyar a las Partes a lograr una solución mutuamente satisfactoria de la controversia la Comisión tiene las siguientes alternativas: 
(a) convocar asesores técnicos o crear los grupos de trabajo o de expertos que considere necesarios;

(b) recurrir a los buenos oficios, la conciliación, la mediación o a otros procedimientos de solución de controversias; o

(c) formular recomendaciones,

De esta amplia gama de alternativas las Comisión puede determinar la que estime se adecue más a lo que las Partes requieren para resolver el conflicto que las afecta.

También existe la posibilidad de acumular dos o más procedimientos de que conozca relativos a una misma medida o referentes a otros asuntos de los que conozca conforme a este artículo, cuando considere conveniente examinados conjuntamente.

\section{3). Procedimiento de solución ante los paneles arbitrales.}

Cuando la Comisión se haya reunido conforme a lo establecido en el punto anterior, y el asunto no se hubiere resuelto dentro de los 30 días posteriores a la reunión o en cualquier otro plazo que las Partes pudieren acordar, cualquiera de estas podrá solicitar por escrito el establecimiento de un panel arbitral. La Parte solicitante entregará la solicitud a su sección del Secretariado y a la otra Parte.

A la entrega de la solicitud, la Comisión establecerá un panel arbitral. A menos que las Partes acuerden otra cosa, el panel se integrará y desempeñará sus funciones en concordancia con las disposiciones de este capítulo.

Lista de panelistas

Las Partes integrarán a más tardar el 10 de enero de 1998, según lo establece el artículo $\mathrm{N}-\mathbf{0 9}$, y conservarán una lista de hasta veinte individuos que cuenten con las aptitudes y la disposición necesarias para ser panelistas, cuatro de los cuales no podrán ser ciudadanos de ninguna de las Partes. Los miembros de la lista serán designados por mutuo acuerdo, por períodos de tres años, y podrán ser reelectos.

Los miembros de la lista deberán tener conocimientos especializados o experiencia en derecho, comercio internacional, otros asuntos de este Tratado, o en la solución de controversias derivadas de acuerdos comerciales internacionales, y deberán ser elegidos estrictamente en función de su objetividad, confiabilidad y buen juicio; ser independientes, no estar vinculados con cualquiera de las Partes, y no recibir instrucciones de las mismas; y cumplir el código de conducta que establezca la Comisión.

Selección del panel

El panel se integrará por cinco miembros. En primer lugar, las Partes procurarán acordar la designación del presidente del panel dentro de los 15 días siguientes a la entrega de la solicitud para la integración del mismo. En caso de que las Partes no logren llegar a un acuerdo sobre la designación del presidente dentro de este período, una de ellas, 
electa por sorteo, designará como presidente, en el plazo de 5 días, a un individuo que no sea ciudadano de una Parte.

Dentro de los 15 días siguientes a la elección del presidente, cada Parte seleccionará dos panelistas que sean ciudadanos de la otra Parte; y en el evento de que una Parte no seleccione a sus panelistas dentro de ese lapso, estos se seleccionarán por sorteo de entre los miembros de la lista que sean ciudadanos de la otra Parte.

Por lo regular, los panelistas se escogerán de la lista. Cualquier Parte podrá presentar una recusación sin expresión de causa contra cualquier individuo que no figure en la lista y que sea propuesto como panelista por la otra Parte, dentro de los 15 días siguientes a aquel en que se haga la propuesta.

Reglas de procedimiento del Panel

La Comisión establecerá a más tardar en la fecha de entrada en vigor de este Tratado, Reglas Modelo de Procedimiento, conforme a los siguientes principios:

(a) los procedimientos garantizarán como mínimo el derecho a una audiencia ante el panel, así como la oportunidad de presentar alegatos iniciales y réplicas por escrito, $y$

(b) las audiencias ante el panel, las deliberaciones y el informe preliminar, así como todos los escritos y las comunicaciones con el mismo, tendrán el carácter de confidenciales.

Estas reglas se pueden modificar cuando se estime necesario. Ellas están actualmente contenidas en una norma recientemente publicada, cual es el Decreto Supremo No 2.214 , de 18 de mayo del 2000 .

Asesoría de expertos

El panel podrá, a instancia de una Parte, o por su propia iniciativa, recabar la información y la asesoría técnica de las personas o grupos que estime pertinente conforme a los términos y condiciones que estas convengan.

En este momento el asunto puede quedar en manos de personas realmente versadas en los temas que han ocasionado los conflictos que las Partes no han podido resolver, y que por lo general son de una complejidad que los funcionarios públicos que integran la Comisión no necesariamente manejan.

Comités de revisión científica

A instancia de una Parte o, a menos que ambas Partes lo desaprueben, el panel podrá por su propia iniciativa, solicitar un informe escrito a un comité de revisión científica sobre cualesquiera cuestiones de hecho relativas a aspectos relacionados con el medio ambiente, la salud, la seguridad u otros asuntos científicos planteados por una Parte en el proceso, conforme a los términos y condiciones que estas convengan.

El comité será seleccionado por el panel de entre expertos independientes altamente 
calificados en materias científicas, después de consultar con las Partes y con los organismos científicos listados en las Reglas Modelo de Procedimiento.

El panel tomará en cuenta el informe del comité y las observaciones de las Partes a este informe, en la preparación de su propio informe.

Informe del Panel

Salvo que las Partes convengan otra cosa, el panel fundará su informe en los argumentos y comunicaciones presentados por las Partes y en cualquier información que haya recibido de conformidad a los procedimientos antes señalados. Dentro de los 90 días siguientes a la elección del último panelista, o en cualquier otro plazo que determinen las Reglas Modelo de Procedimiento, el panel presentará a las Partes un informe preliminar que contendrá:

(a) las conclusiones de hecho,

(b) la determinación sobre si la medida en cuestión es o puede ser incompatible con las obligaciones derivadas de este Tratado, o es causa de anulación o menoscabo, o cualquier otra determinación solicitada en los términos de referencia; y

(c) sus recomendaciones, cuando las haya, para la solución de la controversia.

Los panelistas podrán emitir votos particulares sobre cuestiones en que no exista acuerdo unánime.

Una Parte podrá hacer observaciones por escrito al panel sobre el informe preliminar dentro de los 14 días siguientes a su presentación.

En este caso y luego de examinar las observaciones escritas, el panel podrá, de oficio o a petición de alguna Parte:

(a) solicitar las observaciones de una Parte,

(b) reconsiderar su informe; $y$

(c) llevar a cabo cualquier examen ulterior que considere pertinente.

Informe final del Panel

El panel presentará a las Partes un informe final y, en su caso, los votos particulares sobre las cuestiones en que no haya habido acuerdo unánime, en un plazo de 30 días a partir de la presentación del informe preliminar, a menos que las Partes convengan otra cosa.

Las Partes comunicarán confidencialmente a la Comisión el informe final del panel, dentro de un lapso razonable después de que se les haya presentado, junto con cualquier otro informe de un comité de revisión científica, y todas las consideraciones escritas que una Parte desee anexar.

El informe final del panel se publicará 15 días después de su comunicación a la Comisión, salvo que la Comisión decida otra cosa. 
Cumplimiento del informe final de los paneles

Una vez recibido el informe final del panel, las Partes convendrán en la solución de la controversia, la cual, por lo regular, se ajustará a las determinaciones y recomendaciones de dicho panel, y notificarán a sus secciones del Secretariado toda resolución que hayan acordado respecto de cualquier controversia.

Siempre que sea posible, la resolución consistirá en la no ejecución o en la derogación de la medida disconforme con este Tratado o que sea causa de anulación o menoscabo. A falta de tal resolución, podrá otorgarse una compensación.

Suspensión de beneficios

Si en su informe final un panel ha resuelto que una medida es incompatible con las obligaciones de este Tratado o es causa de anulación o menoscabo y la Parte demandada no ha llegado a un acuerdo con la Parte reclamante sobre una solución mutuamente satisfactoria, dentro de los 30 días siguientes a la recepción del informe final, la Parte reclamante podrá suspender la aplicación de beneficios de efecto equivalente a la Parte demandada, hasta el momento en que alcancen un acuerdo sobre la resolución de la controversia.

Al examinar los beneficios que habrán de suspenderse, la Parte reclamante procurará primero suspender los beneficios dentro del mismo sector o sectores que se vean afectados por la medida, o por otro asunto que el panel haya considerado incompatible con las obligaciones de este Tratado, o que haya sido causa de anulación o menoscabo, y si la Parte reclamante considera que no es factible ni eficaz suspender beneficios en el mismo sector o sectores, podrá suspender beneficios en otros sectores.

Revisión de la medida de suspensión

A solicitud escrita de una Parte, la Comisión instalará un panel que determine si es manifiestamente excesivo el nivel de los beneficios que la otra Parte haya suspendido.

Los procedimientos del panel se seguirán de acuerdo con las Reglas Modelo de Procedimiento que según se dijo fueron recientemente publicadas en el año 2000 .

El panel presentará su informe dentro de los 60 días siguientes a la elección del último panelista, o en cualquier otro plazo que las Partes acuerden.

\section{V.- Procedimientos internos y solución de controversias comer- ciales privadas.}

Cuando una cuestión de interpretación o de aplicación de este Tratado surja en un procedimiento judicial o administrativo interno de una Parte y cualquier Parte considere que amerita su intervención, o cuando un tribunal u órgano administrativo solicite la opinión de una de las Partes, esa Parte lo notificará a su sección del Secretariado y a la otra Parte. La Comisión procurará, a la brevedad posible, acordar una respuesta adecuada. 
La Parte en cuyo territorio se encuentre ubicado el tribunal o el órgano administrativo, presentará a estos cualquier interpretación acordada por la Comisión, de conformidad con los procedimientos de ese foro.

Cuando la Comisión no logre llegar a un acuerdo, cada Parte podrá someter su propia opinión al tribunal o al b́rgano administrativo, de acuerdo con los procedimientos de ese foro.

Ninguna de las Partes podrá otorgar derecho de acción en su ley interna contra la otra Parte con fundamento en que una medida de la otra Parte es incompatible con este Tratado.

\section{VI.- Medios alternativos para la solución de controversias.}

En la mayor medida posible, cada Parte promoverá y facilitará el recurso al arbitraje y a otros tipos de medios alternativos para la solución de controversias comerciales internacionales entre particulares en la zona de libre comercio.

A tal fin, cada Parte dispondrá procedimientos adecuados que aseguren la observancia de los convenios de arbitraje y el reconocimiento y ejecución de los laudos arbitrases que se pronuncien en esas controversias. Se considerará que una Parte cumple con esto, si es parte y se ajusta a las disposiciones de la Convención de Naciones Unidas sobre el Reconocimiento y Ejecución de Sentencias Arbitrales Extranjeras, de 1958, o de la Convención Interamericana sobre Arbitraje Comercial Internacional, de 1975.

La Comisión establecerá un Comité Consultivo de Controversias Comerciales Privadas integrado por personas que tengan conocimientos especializados o experiencia en la solución de controversias comerciales internacionales privadas. El Comité presentará informes y recomendaciones a la Comisión sobre cuestiones generales enviadas por ella relativas a la existencia, uso y eficacia del arbitraje y otros procedimientos para la solución de tales controversias en la zona de libre comercio. 